\title{
A Physiological Study of the Germination of Helianthus annuus. II. The Oily Reserve.
}

BY

\author{
EDWIN C. MILLER.
}

T $\mathrm{N}$ a previous paper ${ }^{1} \mathrm{I}$ reported a study of the general chemical changes 1 which occur in the reserves of the seed of the sunflower during different stages of its germination, and concluded that the carbohydrates which appear in the seedling during germination have their origin in the oily reserve. Only a slight study of the oil itself was made at that time, however, so that it was thought advisable to make a further study of it at different stages in the development of the seedling in order to determine what changes it might undergo during germination.

In the previous paper a review was given of the work carried on by different investigators on the changes which take place in oily seeds during their germination as far as references to these works could be found. One paper, however, which escaped my observation, might well be reviewed here. Deleano, ${ }^{2}$ in a study of the seed and seedling of Ricinus communis, could not detect the smallest trace of free fatty acid or glycerine at any stage of the seedling. He observed that the quantity of reducing sugar at the time when the disappearance of the oil was most rapid, was small compared to the amount of oil which disappeared, but that the amount of substances soluble in water at that time was large. He found also that the quantity of catalase diminished as the oil disappeared. From these observations he reached the conclusion that the oil contained in the seed as a reserve is not saponified in the cells at all, but that it is transformed into soluble compounds which are easily translocated to the growing parts. These compounds, then, give rise to the carbohydrates which are found in the seedling. He also believes that the catalase plays some part in the transformation of the oil. In the present paper reference will be made only to

\footnotetext{
1 Miller, Edwin C. : A Physiological Study of the Germination of Helianthus annuns. Ann, of Bot., vol. xxiv, I910, pp. 693-726.

2 Deleano, N. T.: Recherche chimique sur la germination. Arch. Sci. Biol. (St. Petersb.), xv, I9I0, No. I, pp. I-24. Centralbl. f. Bakt., 2. Abt., vol. xxiv, 1909, Nos. 5-7, pp. I30-I 46.
}

[Annals of Botany, Vol. XXVI. No. CIII. July, 19נ2.] 
those investigations which are deemed necessary for a clear discussion of the results obtained.

\section{Stages of the SeEdling EXamined.}

The oil was examined in the resting seed and in five different stages of the seedling. The stages examined were the same as those studied in the previous investigation with the exception of Stage I. Previously the first examination of the seedling was made when the hypocotyls and roots had attained a length of 2.5 to $3.5 \mathrm{~cm}$. Experience showed, however, that it was difficult to obtain a sufficient quantity of hypocotyls and roots to yield the amount of oil necessary for the determinations that were to be made. The seedlings, therefore, were first examined at a later stage of development, when the roots and hypocotyls had a length of 3.5 to $5 \mathrm{~cm}$. The seedling reached this stage in about three and a half to four days.

A brief description of the last four stages of the seedling examined is given here for convenience. If a more detailed explanation is desired, the description and figures of the different stages may be consulted in the former paper.

Stage II. The hypocotyls and roots had a length of from 7.5 to I I cm., and the arch of the hypocotyl was just breaking through the surface of the ground. The cotyledons had not yet emerged from the seed-coat. The seedlings reached this stage about five days after the planting of the seed.

Stage III. At this stage the hypocotyls had reached a length of from 5 to $6 \mathrm{~cm}$. above the surface of the ground, and the main roots were about the same length with numerous side roots about 2.5 to $3.5 \mathrm{~cm}$. in length. The cotyledons were a bright green, and were spread out perpendicular to the hypocotyl. The plumule had not yet developed. The time required for the seedling to reach this stage was about seven days.

Stage IV. The hypocotyls had now a length of from 8 to $10 \mathrm{~cm}$. from the surface of the ground to the cotyledons. The main roots had reached a length of 6 to $7 \mathrm{~cm}$., and had developed an abundant growth of lateral roots. The cotyledons had broadened and lengthened, and the plumule was slightly developed. The young plant reached this stage of development in about ten days after the planting of the seed.

Stage V. The seedling at this stage differed little from that of Stage IV in general appearance, except that the plumule was more fully developed, and the cotyledons had become more leaf-like. The seedling reached this stage in about fourteen days after the seed was planted.

\section{Preparation of Material for Analysis.}

I. Preparation of Dry Material. The seedlings for this experiment were grown in ordinary quartz sand in the greenhouse. As soon as the 
seedlings had reached the desired stage of development, they were taken up and washed free from the sand. The hypocotyls were then separated from the cotyledons, and the two parts then ground up separately in an ordinary meat chopper. The ground material was then covered with 95 per cent. alcohol and left until it could be treated further.

Previous experience had shown that the ether extract of the sunflower seed and seedling is very easily oxidized. In order to prevent oxidation, or to reduce it to a minimum in the preparation of the dry material of the seed and seedling, the following method was used:

The alcoholic material was placed in two litre glass jars, the lids of which were provided with 'Bunsen valves'. These jars were placed on the steam bath, and the alcohol and water driven off as nearly as possible. The material was then transferred from the jars to large desiccators and dried in vacuo over sulphuric acid. When the material was dry it was thoroughly pulverized and placed again in vacuo over sulphuric acid until ready for use.

II. Preparation of the Ether Extract. The dry powdered material was placed in a large Soxhlet extraction apparatus and extracted for sixteen hours with absolute anhydrous ether. The ethereal solution was then placed on the water bath, and a portion of the ethereal solution distilled off. The concentrated ethereal solution was then placed in a desiccator, and the ether evaporated in vacuo over sulphuric acid until no trace of it remained in the oil. The ether extract was then transferred to small tightly corked bottles until ready for use.

III. Preparation of the Neutral Oil. It was thought advisable to examine the neutral oil at the various stages of development of the seedling, in order to ascertain what changes, if any, it might undergo as compared to those taking place in the entire ether extract. The method used for obtaining the neutral oil was as follows :

95 per cent. alcohol was added to the ether extract in the proportion of 10 grammes of ether extract to 50 c.c. of alcohol. The mixture was placed on the steam bath and heated to boiling, and then titrated with $\frac{\mathrm{N}}{10}$ sodium hydroxide, using phenolphthalein as an indicator. To the cooled mixture was then added an equal volume of petroleum ether, and the mixture shaken gently in a separatory funnel. In this manner is obtained a separation of a solution of soap in 50 per cent. alcohol, and a solution of neutral oil in petroleum ether. The solution of soap was separated from the petroleum ether solution, and the latter again washed with 50 per cent. alcohol to remove all the soap. The petroleum ether solution was then placed on the water bath and most of the petroleum ether driven off. The concentrated solution was then placed in a closed vessel which was connected with the filter pump, and the vessel heated on the water bath until all trace of the 
petroleum ether was removed. The neutral oil thus obtained was placed in small tightly corked bottles until ready for analysis.

\section{Methods of Analysis.}

Upon the ether extract of the seed and of the cotyledons and hypocotyls at the different stages, the following constants were determined in duplicate: free fatty acid, saponification value, total insoluble acids, total soluble acids, iodine number, and acetyl value. The saponification value, total insoluble acids, total soluble acids, and iodine number were determined for the neutral oil of the seed and cotyledons at the different stages of the seedling. The amount of ether extract in percentage of the dry material and in grammes per Ioo cotyledons and hypocotyls was determined for each stage of the seedling examined.

All of the determinations, with the exception of those noted below, were made according to the official methods of the American Association of Official Agricultural Chemists.

The iodine number was estimated by the method of von Huibl.

For the estimation of the acetyl value the following course was followed :

A quantity of oil was heated for two hours with twice its volume of acetic anhydride in a round-bottomed flask with a reflux condenser. The acetylated oil was then transferred to a large beaker and boiling water added. After boiling for half an hour the water was siphoned off. This process was repeated a second and a third time, after which the acetylated oil was shaken up with petroleum ether in a separatory funnel in order to remove all the water from the oil. The petroleum ether solution of the acetylated oil was then placed on the water bath and part of the petroleum ether distilled off. The concentrated solution was then transferred to a closed vessei connected with the filter pump, and the vessel heated on the water bath until all the petroleum ether was driven off. A weighed portion of the oil thus acetylated was then saponified in the usual manner and the acetyl saponification value determined. The excess of sodium hydroxide was titrated with $\frac{\mathrm{N}}{2} \mathrm{HCl}$, the alcohol driven off on the water bath and the acids precipitated by $\frac{\mathrm{N}}{2}$ sulphuric acid. The flask containing the precipitated acid was then filled to the neck with boiling water and heated on the steam bath, until the insoluble acids collected in a layer at the top of the flask. The insoluble acids were then solidified by the immersion of the flask in ice water, after which the liquid content of the flask was filtered and the filtrate collected. Hot water was again added to the flasks, and the same process repeated a second and third time. The collective filtrates were then 
titrated with $\frac{\mathrm{N}}{\mathrm{IO}}$ sodium hydroxide, using phenolphthalein as an indicator.

From the amount of sodium hydroxide necessary to titrate the filtrate was deducted the amount accounted for by the quantity of free acid present in the acetylated oil used in the determination. The number of centimetres of $\frac{\mathrm{N}}{10}$ sodium hydroxide after this correction was multiplied by $5.6 \mathrm{I}$ and the product divided by the weight in grammes of the oil used to determine the acetyl value. A further correction was made for the amount of soluble glycerides present in the ether extract of the cotyledons in Stage V of the seedling.

\section{Discussion of Analytical Results.}

The results obtained in this investigation are shown in the following tables. Table I gives the values of the constants obtained for the ether extract and neutral oil of the seed and the cotyledons at the various stages examined. Table II gives the results of the work upon the ether extract of the hypocotyls and roots at the five different stages of the seedling. The values obtained at the different stages of the seedling for any given constant of the oily material are discussed under separate headings. For the convenience of the botanical reader a brief discussion is given of the physiological significance of each of the various constants that were determined.

Ether Extract. The oily material of the seed of the sunflower composes $54 \cdot \mathrm{I}$ per cent. of its dry weight. At Stage I, when the hypocotyls have reached a length of 3.5 to $5 \mathrm{~cm}$., over one-third of this reserve has disappeared from the cotyledons. In the germination of the sunflower seed, then, it appears that the oily reserve begins to disappear at a very early stage. As shown in the previous paper, three days after the planting of the seed, when the hypocotyls and roots had a length of only 2.5 to $3.5 \mathrm{~cm}$., over one-fifth of the original oil had disappeared. Seven days after planting the seed, when the cotyledons have reached the surface of the ground and spread out perpendicular to the hypocotyl, two-thirds of the original oil has disappeared from the cotyledons. An examination of the seedling fourteen days after planting of the seed shows that 8.7 per cent. of the dry weight of the cotyledons consists of ether extract, and that 5.3 per cent. of the original amount of oil is present in them.

In the roots and hypocotyls the percentage of ether extract decreases from 9.9 per cent. of the dry weight in Stage I to I. 8 per cent. in Stage V, but the quantity of oil per 100 hypocotyls and roots remains practically constant. The fact that the actual amount of ether extract present in the roots and hypocotyls remains almost constant during different stages of the seedling was shown by the results in the former paper, and has been noted 
by Peters ${ }^{1}$ for the seedlings of Cucurbita, Pcpo, and by Schmidt ${ }^{2}$ for the sunflower and other seedlings.

TABLE I.

Chemical Nature of the Oily Reserve.

Cotyledons.

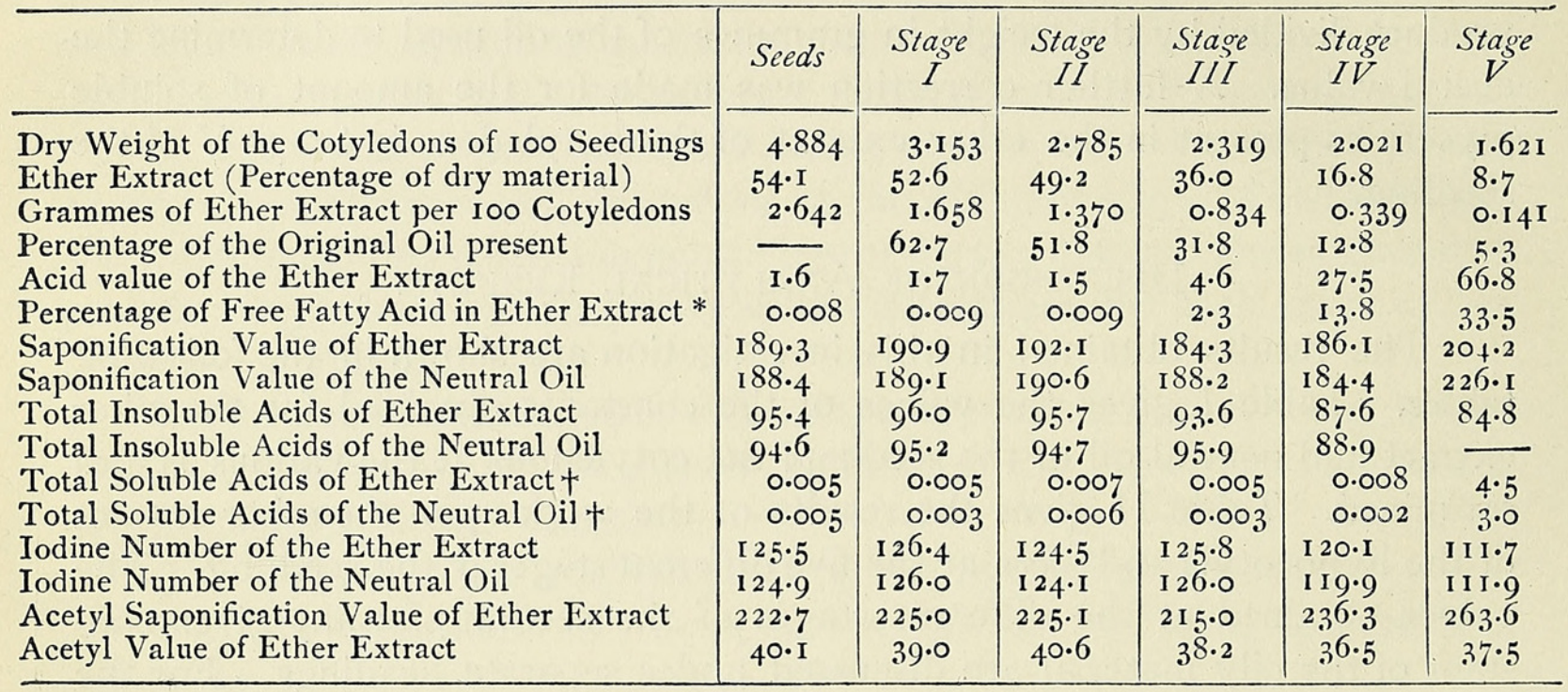

TABLE II.

Chemical Nature of Ether Extract.

Hypocotyls and Roots.

Dry Weight of the Hypocotyls of roo Seedlings Ether Extract (Percentage of dry material)

Grammes of Ether Extract per roo Hypocotyls

Acid Value of Ether Extract

Percentage of Free Fatty Acid in Ether Extract*

Saponification Value of Ether Extract

Total Insoluble Acids in Ether Extract

Total Soluble Acids in Ether Extract $\uparrow$

Iodine Number of Ether Extract

Acetyl Saponification Value of Ether Extract

Acetyl Value of Ether Extract

\begin{tabular}{|c|c|c|c|c|}
\hline $\begin{array}{c}\text { Stage } \\
I\end{array}$ & $\begin{array}{c}\text { Stage } \\
\text { II }\end{array}$ & $\begin{array}{c}\text { Stage } \\
\text { III }\end{array}$ & $\begin{array}{c}\text { Stage } \\
I V\end{array}$ & $\begin{array}{c}\text { Stage } \\
V\end{array}$ \\
\hline 0.605 & 0.885 & $1.2 \mathrm{I}$ & $I \cdot 52$ & $2 \cdot 17$ \\
\hline $9 \cdot 9$ & $7 \cdot 4$ & $3 \cdot 8$ & $3 \cdot I$ & I. 8 \\
\hline 0.060 & $0.06_{5}$ & 0.046 & 0.047 & 0.040 \\
\hline I 8.2 & 24.0 & $27 \cdot I$ & $5^{8 \cdot 3}$ & $97^{\circ} 8^{\circ}$ \\
\hline $9 \cdot I$ & I 2.0 & I 3.4 & $26 \cdot 4$ & $49 \cdot I$ \\
\hline 190.3 & $189 \cdot 2$ & I 98.4 & $236 \cdot 9$ & $23^{8} \cdot 3$ \\
\hline $89 \cdot 6$ & $85 \cdot 6$ & $86 \cdot 5$ & $67 \cdot I$ & $57 \cdot 2$ \\
\hline I.O & I. 6 & I. 8 & I $6 . I$ & I 8.5 \\
\hline I I $5 \cdot 7$ & 1 I 8.8 & $9^{6 \cdot I}$ & 72.6 & $4^{8 \cdot 3}$ \\
\hline $25 \mathrm{I} \cdot 4$ & $300 \cdot 0$ & $274 \cdot 8$ & - & - \\
\hline $7 \mathrm{I} \cdot 2$ & I I 4.0 & $95 \cdot I$ & - & - \\
\hline
\end{tabular}

+ Estimated as butyric acid.

* Estimated as oleic acid.

Acid Value. By the acid value of an oil is meant the number of milligrams of caustic potash necessary to neutralize one gramme of the oil. It is

1 Peters, Ed. : Zur Keimungsgeschichte des Kürbissamens. Versuchs-Stationen, iii, I86r, pp. I-9.

2 Schmidt, R. H. : Ueber Aufnahme und Verarbeitung von fetten Oelen durch Pflanzen. Flora, lxxiv, I $89 \mathrm{I}$, p. 300. 
thus a measure of the amount of free fatty acid present in the oil, and indicates the degree of hydrolysis which it has undergone. The acid value of the ether extract of the seed is only I. 6 , and this value remains constant for the oily matter of the cotyledons for the first two stages of the seedlings, until one-half of the ether extract has disappeared. In Stage III the value has risen to only 4.6. This value increases to $\mathrm{I} 2.8$ in Stage IV and to 66.8 in Stage V, when only 5.3 per cent. of the original ether extract remains in the cotyledons. The acid value of the ether extract of the hypocotyls and roots is $I 8.2$ in Stage I, and gradually increases until it has a value of 97.8 in the last stage examined.

The acid value, however, indicates nothing as to the nature of the free acids present in the ether extract. They may represent organic acids other than the fatty acids, since many of the former are soluble in ether and would thus be present in the ether extract. In this investigation no attempt was made to identify the free acids present in the ether extract, and they were arbitrarily calculated as oleic acid. If fatty acids of lower molecular weight, however, are present, the value obtained would indicate a greater percentage of free fatty acid than really occurs.

The amount of free fatty acid estimated as oleic is less than I per cent. of the ether extract of the seed, and that value remains constant for the oily extract of the cotyledons until Stage III of the seedling, when it amounts to 2.3 per cent. of the ether extract present in the cotyledons. The amount gradually increases until it constitutes one-third of the oily material present in the cotyledons at the last stage examined. Some of the free acids present in the ether extract of the cotyledons at the later stages of the seedling are those of low molecular weight and soluble in water, as the estimation of the total soluble acids shows. Not all the free acids, however, are those of the lower groups, for the determination of the soluble acids present in the oil shows a quantity too small to account for all the free acid present in the ether extract of the cotyledons. For example, take the ether extract of the cotyledons at Stage IV. The free fatty acid calculated as oleic that is present in the oily material amounts to 13.8 per cent. If the acid were calculated as butyric it would amount to 4.3 per cent. of the ether extract. But the total quantity of soluble free and combined fatty acids, estimated as butyric, at that stage amounts to less than I per cent. of the ether extract. It seems probable, then, that most of the free acids present in the ether extract of the cotyledons represent those of higher molecular weight than those that are soluble in water.

In the hypocotyls and roots the amount of free fatty acid, estimated as oleic, increases from 9.I per cent. of the ether extract at Stage 1 to 49.I per cent. at Stage V. During the first three stages examined there is evidence that a considerable part of the free fatty acid present in the ether extract of the hypocotyls and roots represents acids of higher molecular weight. Thus 
the amount of free acid in the ether extract estimated as butyric gives a value two to three times greater than that found in the estimation of the total soluble acids. In the last two stages, however, the amount of free acid estimated as butyric would be less than that of the total soluble acids shown to be present. This fact is probably due to the presence of glycerides of lower molecular weight in the ether extract at those stages.

From the above it seems evident that in the ether extract of both the cotyledons and hypocotyls of the sunflower free fatty acids of high molecular weight are present. This can be determined definitely, however, only by a qualitative study of the acids present.

Saponification Value. The saponification equivalent or value of an oil is the amount of caustic potash in milligrams that is neutralized during the saponification of one gramme of the oil by the combined and free fatty acids which it contains. It is in reality an indication of the mean molecular weight of the fatty acids which enter into the composition of the oil. Thus oils which are glycerides of the higher fatty acids give a lower saponification value, while those that are glycerides of the lower fatty acids give a higher saponification value.

The saponification value of the ether extract and neutral oil in the cotyledons of the seed is the same. There is no change in the saponification number of either the ether extract or the neutral oil until the last stage of the seedling examined, when only 5.3 per cent. of the original ether extract remains in the cotyledons. The marked increase of the saponification value of both the neutral oil and ether extract at the last stage of the seedling is significant in the fact that it is the first indication given of the presence of glycerides or free fatty acids of lower molecular value than those originally contained in the cotyledons of the seed.

In the hypocotyls and roots the saponification value of the ether extract begins to increase only in the later stages of development of the seedling. It is a very striking fact that the saponification value of the ether extract in the hypocotyls and roots is identical with that of the oil contained in the cotyledons of the seed and seedling up to a period when the hypocotyls and roots have attained a length of 7.5 to II $\mathrm{cm}$. and one-half of the oil originally present in the seed has disappeared. Even after the cotyledons are above ground and spread out perpendicular to the hypocotyl, and after over two-thirds of the original oil has disappeared from the seedling, the saponification value of the ether extract of the hypocotyls and roots has increased but slightly over that of the oil of the cotyledons. Up to the time when two-thirds of the original oil has disappeared from the cotyledons we can say, then, that the saponification values of the oil in the cotyledons and hypocotyls and roots are practically identical with the saponification value of the original oil of the seed.

Total Insoluble Acids. By the total insoluble acids of an oil is meant 
the percentage of fatty acids insoluble in water that is yielded on the saponification of the oil. The determination, then, of the insoluble fatty acids of an oil gives some information as to its composition. Thus, if the oil contained in the seed shows during the course of germination a decrease in the percentage of insoluble fatty acids, it indicates that the higher fatty acids are being replaced by those of the lower groups which are soluble in water.

The percentages of total insoluble fatty acids present in the ether extract and in the neutral oil of the seed are, respectively, $95 \cdot 4$ and $94 \cdot 6$. The values thus are practically identical. These values remain constant for both the neutral oil and ether extract until Stage IV of the seedling, when seveneighths of the original oil of the seed have disappeared. At this period there is a considerable decrease in the amount of insoluble fatty acids in both the neutral oil and the ether extract. The decrease, however, is almost identical in both, so that the amount of insoluble fatty acids remaining in each is practically the same. The amount in the ether extract is 87.6 per cent. and in the neutral oil 88.9 per cent. In the last stage of germination the amount of insoluble fatty acids in the ether extract falls to 84.8 per cent.

The percentage of insoluble fatty acids in the ether extract of the hypocotyls and roots in Stage I when they had reached a length of 3.5 to $5 \mathrm{~cm}$. was $89 \cdot 6$, a value considerably lower than that of the original seed. This value remains the same during the two stages of the seedling, and then rapidly decreases until the value has fallen to 57.2 in the last stage of the seedling examined.

The determination of the insoluble fatty acids indicates that there is no change in the solubility of either the combined or free fatty acids of the oil of the cotyledons until a late stage of development, when nearly all the oil has disappeared. At least, up to that time there is, as will be explained later, no accumulation of soluble acids that can be detected. In the hypocotyls and roots, however, the decrease in the amount of insoluble fatty acids of the ether extract at the first stage of the seedling indicates that in these organs from the beginning of germination the insoluble fatty acids are being replaced to a small extent by the fatty acids which are soluble in water. This replacement becomes very marked in the last two stages of the seedling.

Total Soluble Acids. The total soluble acids of an oil represent both the free and combined acids of the oil which are soluble in water, and represent the fatty acids of lower molecular weight. The amount of acids soluble in water in the ether extract and the neutral oil of the seed is less than I per cent. This value remains almost constant for both until the last stage of the seedling examined, when it suddenly rises to 4.5 per cent. of the ether extract and 3 per cent. of the neutral oil. It seems evident from the results that no fatty acids of the lower series are produced from the oil in the cotyledons until only a small part of the original oil remains. 
The large amount of soluble acids in the neutral oil of the cotyledons in Stage VI indicates that there are present considerable quantities of the glycerides of the lower fatty acids. The quantity of soluble acids in the ether extract of the roots and hypocotyls, however, amounts to I per cent. at the first stage of the seedling and to $\mathrm{I} \cdot 6$ per cent. and $\mathrm{I} \cdot 8$ per cent. respectively in the next two stages. The amount of soluble acid rises rapidly in the last two stages and composes I6.I per cent. and I 8.5 per cent. of the ether extract in Stages V and VI respectively.

The determination of the soluble acids supplements remarkably well the results obtained in the estimation of the total insoluble fatty acids. Wherever there is a decrease in the percentage of insoluble fatty acids there is an increase in the amount of the soluble acids.

The Todine Number. By the iodine number of an oil is meant the amount of iodine that the combined and free unsaturated fatty acids of an oil will take up expressed in percentage of the weight of the oil. It is really a measure of the quantity of unsaturated fatty acids in the oil. Thus, if the iodine number of the oil decreases during germination, it is indicative of the fact that the unsaturated fatty acids of the oil are becoming saturated, probably by the addition of oxygen.

The iodine numbers of the ether extract and neutral oil of the seed are practically identical, being 125.5 and 124.9 respectively. This value holds constant for both the ether extract and neutral oil of the cotyledons until Stage IV, when there is a like decrease in the value of the iodine number of each. The iodine number for each at this stage is 120 . At this period of development seven-eighths of the original oil have disappeared and $\mathrm{I} 3.8$ per cent. of the ether extract remaining is composed of free fatty acid. In the last stage of germination, when only 5.3 per cent. of the original oil remains in the cotyledons, and one-third of the oily material present is composed of free fatty acid, the value of the iodine number for both the ether extract and neutral oil is the same and amounts to III 8 .

These results are significant in that they indicate that neither the combined nor the free fatty acids of the ether extract of the cotyledons show any signs of becoming saturated until a late stage of the seedling, and even then the degree of saturation is comparatively slight. It further indicates that the combined and free fatty acids of the ether extract are equally saturated, and that this is the case even when one-third of the ether extract is composed of free acid.

In my previous work I found that the iodine number of the ether extract in Stages IV and V fell to 77.5 and 67.4 respectively. I attribute this low result, however, to the oxidation of the oil during the preparation of the material. In the preparation of the material for this investigation, however, methods were employed, as explained elsewhere, which reduced the oxidation of the oil to a minimum. 
In the ether extract of the hypocotyls and roots, however, entirely different results are obtained from that of the cotyledons. At Stage I the iodine number has fallen to II $7 \%$. It stays constant during the next stage and then falls rapidly, amounting to only 43.3 in the last stage of the seedling. This indicates that the free and combined fatty acids of the ether extract of the hypocotyls and roots become saturated to a considerable extent at the beginning of germination, and that this saturation becomes more and more complete as germination progresses.

The Acetyl Value. The acetyl value of an oil gives the number of milligrams of caustic potash required to neutralize the acetic acid that is set free when one gramme of the acetylated oil is saponified. The acetyl value is really a measure of the amount of the hydroxyl groups which an oil contains.

The acetyl value of the ether extract of the seed is $40 \cdot$ I. The value remains practically constant for the oily material of the cotyledons during all stages of the seedling. The slight decrease in the acetyl value at the last stages comes within the limit of error of the process. It seems, then, that there is no increase in the amount of the hydroxyl groups of the ether extract of the cotyledons during any stage of germination.

The acetyl value of the ether extract of the roots and hypocotyls was determined for the first three stages of the seedling. The value amounts to $7 \mathrm{I} \cdot 2, \mathrm{II} 4 \cdot 0$, and $95^{\cdot} \cdot \mathrm{I}$ for each of the respective stages. The results are thus much higher than those obtained for the ether extract of the cotyledons. The amount of soluble glycerides present is far too small to account for this high value. It seems, then, that the ether extract of the roots and hypocotyls has a much larger amount of hydroxyl groups than that of the cotyledons.

\section{General Considerations.}

The Oily Material of the Cotyledons. The saponification value, total insoluble acids, total soluble acids, and iodine number of both the ether extract and neutral oil of the cotyledons of the seedling remain constant up to the time when seven-eighths of the original oily reserve present in the seed has disappeared. A marked change in these values takes place only in the last stage examined, when only 5.3 per cent. of the original oil remains in the cotyledons. The change in values for the above constants indicates that the oily material at that stage consists to a small extent of glycerides and free fatty acids of lower molecular weight than those composing the original oily reserve of the seed. The change in the iodine number indicates that both the free fatty acids and glycerides are becoming partially saturated, probably by the addition of oxygen.

The acetyl value of the ether extract remains constant for all stages of the seedling, and indications are thus given that the amount of hydroxyl 
groups of the oily material remains the same until all the reserve has disappeared from the cotyledons.

The only marked change in the nature of the oily reserve in the cotyledons is the increase in the amount of free acid present. The acid value of the oily reserve remains constant until over two-thirds of the ether extract have disappeared from the cotyledons, when it rises to $4 \cdot 6$.

The most marked change in the ether extract at the last stage of seedling examined is the amount of free acid present. The acid value of the ether extract at that stage is $60 \cdot 8$. Calculated as oleic acid the amount of free acid present would amount to one-third of the oily material found in the cotyledons at that stage. Some of the free acids present, however, are of low molecular weight and soluble in water; but the greater part of the free acid is composed of fatty acids of high molecular weight which are insoluble in water.

The results obtained in this investigation indicate that, with the exception of an increase in the amount of free acid, no change takes place in the oily reserve of the cotyledons until nineteen-twentieths of the oil originally present has disappeared from them.

The Oily Material of the Hypocotyls and Roots. The saponification value of the ether extract of the hypocotyls is practically the same for the first three stages of the seedling examined as that of the ether extract of the cotyledons at those stages. After the third stage of the seedling the saponification value increases rapidly.

The amount of insoluble fatty acids remains constant during the first three stages, but is about Io per cent. less than the amount of insoluble acid present in the ether extract of cotyledons at the same stages. After that the amount of insoluble fatty acids falls rapidly and amounts to only $57 \cdot 2$ per cent. of the oily material present at the last stage of the seedling. The amount of soluble fatty acids during the first three stages increases but little, but the amount present is greater than that found in the ether extract of the cotyledons during those respective stages. During the last two stages of the seedling the amount of soluble fatty acids increases rapidly, and amounts to 18.5 per cent. of the oily matter at the last stage of the seedling. The acid value increases gradually from 18.2 at the first stage of the seedling to $97 \cdot 8$ at the last stage examined. During the first three stages there is evidence that a considerable portion of the free acid is composed of acids of higher molecular weight which are insoluble in water. During the last two stages, however, the free acids present seem to be composed entirely of those of low molecular weight which are soluble in water.

The iodine number is constant for the first two stages, but is considerably less than that of the ether extract of the cotyledons at that time; after the second stage of the seedling the iodine value falls rapidly and amounts to only $48 \cdot 3$ at the last stage examined. 
The acetyl value for the first three stages averages about twice as great as that of the ether extract of the cotyledons at the respective stages.

It will be noticed that the constants which were determined for the ether extract of the hypocotyls and roots for the first three stages have a striking resemblance to those of the ether extract of the cotyledons during those stages. The results indicate, however, that the changes in the oily material during the first two stages consist in a gradual but evident breaking down of the higher free fatty acids and glycerides into those of lower molecular weight, the saturation of the fatty acids, and an increase in the amount of the hydroxyl groups present. During the last two stages, however, these changes are rapid and very marked, as indicated by the value of the different constants determined.

\section{SUMMARY.}

I. The acid value of the ether extract of the seed is low, amounting to only $\mathrm{I} \cdot 6$, and this value remains the same for the oily material of the cotyledons until two-thirds of the oily reserve has disappeared from them. After that the acid value increases rapidly. There is evidence that the greater part of the free acid present in the ether extract at all the stages is composed of free fatty acids of high molecular weight which are insoluble in water.

2. The results obtained indicate that, with the exception of the increase in the amount of free acid, no change takes place in the oily reserve remaining in the cotyledons until the last stage, when the seedling has become an independent plant. At that stage only 5.3 per cent. of the original oily reserve remains in the cotyledons.

3. The results indicate that the change taking place in the oily material of the cotyledons when only $5 \cdot 3$ per cent. of the oily reserve remains, consist in a breaking down of the higher fatty acids and glycerides into those of lower molecular weight, a partial saturation of the free and combined fatty acids, and a marked increase in the amount of free acid.

4. The amount of oily material contained in the hypocotyls and roots remains practically constant for all stages of the seedling examined.

5. Some of the constants of the oily material of the hypocotyls and roots during the first three stages of the seedling have a striking resemblance to those of the oily reserve of the cotyledons at those stages. The results in general, however, show that during these stages there has occurred a gradual but well defined breaking down of the oily material into free fatty acids and glycerides of low molecular weight, a marked saturation of the fatty acids, and an increase in the amount of the hydroxyl group of the oily matter. During the last two stages of the seedling these changes are very rapid and very marked.

Kansas State Agricultural College, MaNHATTAN, Kansas. 


\section{$2 \mathrm{BHL}$ Biodiversity Heritage Library}

Miller, Edwin C . 1912. "A physiological study of the germination of Helianthus annuus. II. The oily reserve." Annals of botany 26, 889-901. https://doi.org/10.1093/oxfordjournals.aob.a089421.

View This Item Online: https://www.biodiversitylibrary.org/item/236930

DOI: https://doi.org/10.1093/oxfordjournals.aob.a089421

Permalink: https://www.biodiversitylibrary.org/partpdf/319934

\section{Holding Institution}

Smithsonian Libraries

\section{Sponsored by}

Biodiversity Heritage Library

\section{Copyright \& Reuse}

Copyright Status: Not in copyright. The BHL knows of no copyright restrictions on this item.

This document was created from content at the Biodiversity Heritage Library, the world's largest open access digital library for biodiversity literature and archives. Visit BHL at https://www.biodiversitylibrary.org. 